\author{
Rachel S. Agbeko \\ Jeffrey P. Burns \\ Mark J. Peters
}

\section{Tools for revealing uncomfortable truths? Measuring child-centred health-related quality of life after paediatric intensive care}

Received: 5 May 2015

Accepted: 6 May 2015

Published online: 3 June 2015

(C) Springer-Verlag Berlin Heidelberg and ESICM 2015

\section{R. S. Agbeko ( $\bullet)$}

Department of Paediatric Intensive Care, Great North Children's Hospital, The Newcastle upon Tyne Hospitals NHS Foundation Trust, Institute of Cellular Medicine, Newcastle University, Newcastle upon Tyne, UK

e-mail: rachel.agbeko@ncl.ac.uk

\section{J. P. Burns}

Division of Critical Care Medicine, Department of Anaesthesia, Perioperative and Pain Medicine, Boston Children's Hospital, Harvard Medical School, Boston, MA, USA

\section{J. Peters}

Respiratory, Critical Care and Anaesthesia Unit, Paediatric Intensive Care Unit, UCL Institute of Child Health, Great Ormond Street Hospital NHS Trust, London, UK

The benefits of paediatric intensive care units (PICU) are self-evident. Mortality rates for critically children have declined dramatically [1]. The greatest gains are occurring in higher-risk groups in whom the appropriateness of critical care was previously questioned. For example, those with malignancies [2] fare better and require a more optimistic approach than hitherto thought [3].

In this edition of Intensive Care Medicine, Dr. Aspesberro et al. [4] further this point: that mortality per se has ceased to be a meaningful outcome measure for the majority of paediatric intensive care admissions. Their response is to attempt to identify more meaningful outcome measures from the health-related quality of life (HRQL) literature published between 1980 and 2015 in the context of paediatric critical care.

The review is timely, important and uncomfortable. Timely, because there is a growing appreciation that the provision of paediatric intensive care is associated with increased morbidity [5]. Why? Perhaps at least in part because there has been a shift in PICU casemix from 'acute' to 'acute on chronic' critical illness. A recent study from the USA identified that $53 \%$ of critically ill children had pre-existing chronic complex illnesses [6]. This change has many implications. One major implication is that the HRQL outcomes that might be hoped for many of our patients are becoming more distinct from those of previously healthy children [7].

This subject is important, because paediatric intensive care is costly: for the child, their family and society. Equally, the association of increased morbidity with improved mortality should make intensivists uncomfortable, as now we enter an era where the outcomes shift from the "hard" objective, binary 'life or death' outcome to the more "fuzzy" concept of HRQL.

The World Health Organisation (WHO) defines health as "a state of complete physical, mental and social wellbeing and not merely the absence of disease or infirmity" [8].

Ironically, this definition will render most of us unhealthy most of the time as the emphasis is on "complete" well-being. Moreover, the WHO definition of health does not do justice to resilience and the capacity to adapt and function well with chronic disease or disability. This understanding prompted a group of international health experts to reframe health as the ability to adapt and self-manage [9]. Adaptation and resilience are vital attributes to successfully navigate through childhood, and self-management is increasingly relevant to children as they grow older. Thus, the concept of "health" requires a more operational framework, as well as meticulous measurement, in order to better advance our clinical practice to meet these new outcome goals.

Other high-risk paediatric medical specialties have previously confronted this same challenge of evolving a more empirical basis by which to assess the potential 
Fig. 1 Percentage of children with the same or better health status post PICU by pre-existent health status. In 1982 those with severe disability had worse outcome than those who were previously normal, in 2005/6 there was no difference in health status change between the groups. Data from [1]

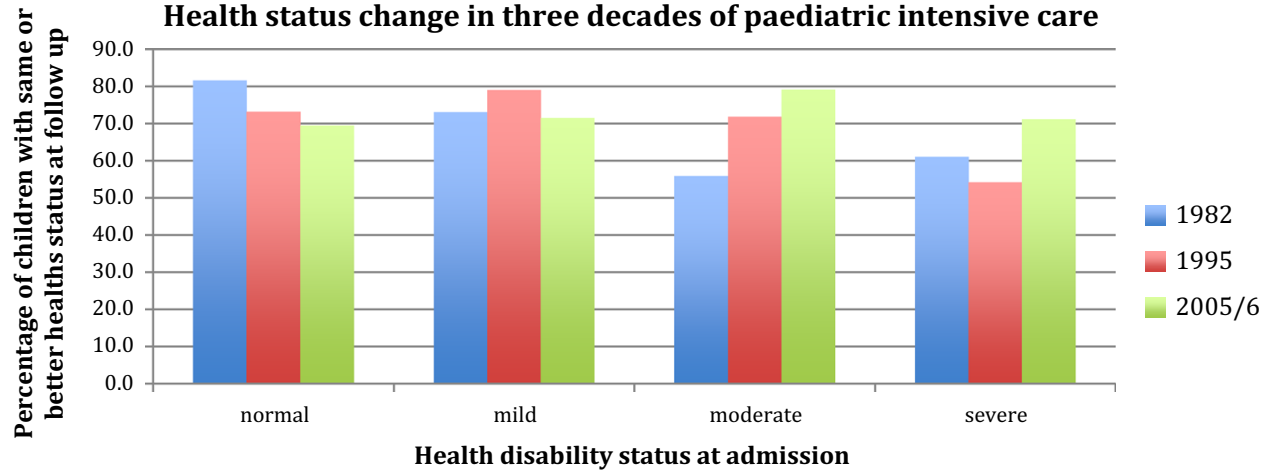

benefit of a therapy. Paediatric oncology has evolved beyond solely assessing mortality to now include also the quality of life for survivors of childhood cancer [10]. Follow-up programs that assess neuro-developmental and complex conditions are now routine in neonatology. However, relatively few paediatric critical care follow-up programs exist and prospective studies describing wellbeing after PICU stay are scarce [11].

Which patients can benefit from paediatric intensive care might be seen in absolute or relative terms. The three decades of Melbourne data [1] show that over time the group with pre-existent health needs stands to benefit more than previously healthy children if one defines a "good outcome" as functional status equal to, or better than, prior to admission (Fig. 1). Being able to assess benefit systematically requires more sophisticated tools, however, than are available from historical comparisons.

In this issue of Intensive Care Medicine, Aspesberro and colleagues review the use of HRQL in paediatric critical care [4]. This focused review identified 78 papers that fulfilled the selection criteria. From this review of the literature it is now apparent that many HRQL tools are far from ideal in the paediatric critical care setting. Although they perform well in terms of validity, interpretability and mode of administration, arguably their usefulness is limited because they are arduous to respond to, are not well adapted to the critical care setting or are insensitive to change over time. The authors, however, do identify four HRQL tools that represent the best available to start the iterative process of measuring and assessing paediatric critical care-related HRQL. These tools are the PedsQL ${ }^{\mathrm{TM}}$ 4.0, CHQ-PF28 (both from the USA), KIDSCREEN-27 (international) and KINDL (Germany).

There are several reasons to create an empirical evidence base for outcome after PICU. While the paediatric critical care community likely accepts that mortality has ceased to be the only pertinent outcome measure to describe health benefit in critically ill children, we have been slow to shift our focus to morbidity or HRQL. The reasons for this may be in part because of unfamiliarity with measurement tools, difficulties in assessing baseline functioning and anticipated development. Could it also be that our scientific model has been anchored too long in a culture that prefers $p$ values above the narrative of qualitative research?

Further, as health care workers, we are now also doing our job in the epoch of emotive discussions on social media and a high value placed on parental autonomy [12].

Finally, from a rather different perspective, outcome measures might also inform us when we face decisions in times of scarcity. Outcome measures such as HRQL may open the door to the development of more transparent admission triage criteria in resource-limited environments [13].

Paediatric intensive care is transitioning from a specialty that deals with acute illness to one that is part of the multidisciplinary team that looks after children with chronic illness. Aspesberro and colleagues provide an important advance for the field with this review of HRQL tools that will better allow us to measure and analyse a broader range of important outcomes of paediatric critical care.

This review joins two recent systematic reviews on measurement tools for post intensive care admission functional physical [14] and psychosocial health status in adults [15]. All three rightly call for a standardized way in which we evaluate recovery and outcome after intensive care admission.

Conflicts of interest On behalf of all authors, the corresponding author states that there is no conflict of interest. 


\section{References}

1. Namachivayam P, Shann F, Shekerdemian L, Taylor A, van Sloten I, Delzoppo C, Daffey C, Butt W (2010) Three decades of pediatric intensive care: who was admitted, what happened in intensive care, and what happened afterward. Pediatr Crit Care Med 11:549-555

2. Zinter MS, DuBois SG, Spicer A, Matthay K, Sapru A (2014) Pediatric cancer type predicts infection rate, need for critical care intervention, and mortality in the pediatric intensive care unit. Intensive Care Med 40:1536-1544

3. Peters MJ, Agbeko RS (2014) Optimism and no longer foolishness? Haematology/oncology and the PICU. Intensive Care Med 40:1589-1591

4. Aspesberro F, Mangione-Smith R, Zimmerman JJ (2015) Health-related quality of life following pediatric critical illness. Intensive Care Med. doi: 10.1007/s00134-015-3780-7

5. Pollack MM, Holubkov R, Funai T, Clark A, Berger JT, Meert K, Newth CJ, Shanley T, Moler F, Carcillo J, Berg RA, Dalton H, Wessel DL, Harrison RE, Doctor A, Dean JM, Jenkins TL, Eunice Kennedy Shriver National Institute of Child Health and Human Development Collaborative Pediatric Critical Care Research Network (2014) Pediatric intensive care outcomes: development of new morbidities during pediatric critical care. Pediatr Crit Care Med 15:821-827
6. Edwards JD, Houtrow AJ, Vasilevskis EE, Rehm RS, Markovitz BP, Graham RJ, Dudley RA (2012) Chronic conditions among children admitted to U.S. pediatric intensive care units: their prevalence and impact on risk for mortality and prolonged length of stay. Crit Care Med 40:2196-2203

7. Rennick JE, Childerhose JE (2015) Redefining success in the PICU: new patient populations shift targets of care. Pediatrics 135:e289-e291

8. World Health Organization (1948) Constitution of the World Health Organization: basic document. WHO, Geneva

9. Huber M, Knottnerus JA, Green L, van der Horst H, Jadad AR, Kromhout D, Leonard B, Lorig K, Loureiro MI, van der Meer JW, Schnabel P, Smith R, van Weel C, Smid H (2011) How should we define health? BMJ 343:d4163

10. McCabe MS, Bhatia S, Oeffinger KC, Reaman GH, Tyne C, Wollins DS, Hudson MM (2013) American Society of Clinical Oncology statement: achieving high-quality cancer survivorship care. J Clin Oncol 31:631-640

11. Als LC, Picouto MD, Hau SM, Nadel S, Cooper M, Pierce CM, Kramer T, Garralda ME (2015) Mental and physical wellbeing following admission to pediatric intensive care. Pediatr Crit Care Med. doi: 10.1097/PCC.0000000000000424
12. BBC (2015) Ashya King: Southampton hospital staff criticise parents. http://www.bbc.co.uk/news/ukengland-hampshire-32219005. Accessed 29 April 2015

13. Argent AC, Ahrens J, Morrow BM, Reynolds LG, Hatherill M, Salie S, Benatar SR (2014) Pediatric intensive care in South Africa: an account of making optimum use of limited resources at the Red Cross War Memorial Children's Hospital. Pediatr Crit Care Med 15:7-14

14. Parry SM, Granger CL, Berney S, Jones J, Beach L, El-Ansary D, Koopman R, Denehy L (2015) Assessment of impairment and activity limitations in the critically ill: a systematic review of measurement instruments and their clinimetric properties. Intensive Care Med 41:744-762

15. Jensen JF, Thomsen T, Overgaard D, Bestle MH, Christensen D, Egerod I (2015) Impact of follow-up consultations for ICU survivors on postICU syndrome: a systematic review and meta-analysis. Intensive Care Med 41:763-775 